\title{
Retinoic Acid Facilitates Toll-Like Receptor 4 Expression to Improve Intestinal Barrier Function through Retinoic Acid Receptor Beta
}

\author{
Yingying Li $i^{a, b}$ Yuan Gao ${ }^{a, b}$ Ting Cui ${ }^{a, b}$ Ting Yang ${ }^{a, b}$ Lan Liuc Tingyu Lia,b \\ Jie Chen ${ }^{a, b}$ \\ aChildren's Nutrition Research Center, Children's Hospital of Chongqing Medical University, Chongqing, \\ ${ }^{b}$ Ministry of Education Key Laboratory of Child Development and Disorders, China International Science \\ and Technology Cooperation Base for Child Development and Critical Disorders, Key Laboratory \\ of Pediatrics in Chongqing, Chongqing, China; 'Laboratory of Intestinal Physiology and Pathology, \\ Department of Surgery, University of Maryland School of Medicine, Baltimore, Maryland, USA
}

\section{Keywords}

Intestinal epithelial barrier - Vitamin A - Retinoic acid receptor beta $\cdot$ Toll-like receptor 4 Zonula occluden-2

\begin{abstract}
Background/Aims: Vitamin A (VA) protects the intestinal epithelial barrier by improving cell migration and proliferation. Our previous studies demonstrated that VA deficiency (VAD) during pregnancy suppresses the systemic and mucosal immune responses in the intestines of offspring and that VA supplementation (VAS) during early life can increase immune cell counts. However, little is known about the mechanisms by which VA regulates intestinal epithelial barrier function. Methods: Caco-2 cells were treated with all-trans retinoic acid (ATRA) for 24 hours to determine the optimum ATRA concentration to which the cells in question respond. Caco-2 cells were infected with recombinant adenoviruses carrying retinoic acid receptor beta (Ad-RAR $\beta$ ) and small interfering RAR $\beta(\operatorname{siRAR} \beta)$ to assess the effects of RAR $\beta$ signalling on the expression of specific proteins. A siTLR4 lentivirus was used to knockdown Toll-like receptor 4 (TLR4) in Caco-2 cells to determine its role in the protective effects of VA on the intestinal epithelial barrier, and experiments involving TLR4-knock-out mice were performed to verify the effect of TLR4. VA normal (VAN), VAD and VAS rat models were established to confirm that changes in RAR $\beta$, TLR4 and ZO-2 expression levels that occurred following decreases or increases in retinol concentrations in vivo, and the permeability of the Caco2 cell monolayer, as well as that of the epithelial barrier of the rat intestine was detected by measuring transepithelial resistance (TER) or performing enzyme-linked immunosorbent assay (ELISA). Retinoic acid receptor (RAR), toll like receptor (TLR) and tight junction (TJ) mRNA and protein expression levels in Caco-2 cells and the colon monolayers in the rat and mouse models were measured by PCR and western blotting, respectively. Co-immunoprecipitation (CO-IP) and immunofluorescence staining were performed to assess the interactions among


Li et al.: RAR $\beta$ Regulates TLR4 to Improve Barrier Function

RARß, TLR4 and zonula occluden-2 (ZO-2) in Caco-2 cells, and chromatin immunoprecipitation (ChIP) assay was performed to assess the binding between RAR $\beta$ and the TLR4 promoter sequence in Caco-2 cells. Results: In the present study, ATRA treatment not only increased the TER of the Caco-2 monolayer but also up-regulated the expression levels of RAR $\beta$, TLR4 and ZO-2 in Caco-2 cells. The expression levels of these three proteins were significantly decreased in the colonic epithelial monolayers of VAD rats compared with those of VAN rats and were significantly increased following VAS in the corresponding group compared with the control group. Furthermore, the above changes in TLR4 and ZO-2 expression levels were augmented or attenuated by Ad-RAR $\beta$ or siRAR $\beta$ infection, respectively, in Caco-2 cells. Interestingly, siTLR4 down-regulated ZO-2 expression but did not affect RAR $\beta$ expression in Caco- 2 cells, and in VAD mice the lack of TLR4 did not affect ZO-2 expression. We noted direct interactions between RAR $\beta$ and TLR4, TLR4 and ZO-2 in Caco-2 cells, and ChIP assay showed that RAR $\beta$ could bind to the TLR4 promoter but not the ZO-2 promoter in Caco-2 cells. Conclusion: Taken together, our results indicate that RAR $\beta$ enhanced ZO-2 expression by regulating TLR4 to improve intestinal epithelial barrier function in Caco- 2 cells, as well as in rat and mouse models, but not in humans.

\section{Introduction}

Vitamin A (VA) and its derivatives (i.e., retinol, retinal, and retinoic acid) play important roles in many general biological processes, such as cell proliferation, differentiation and apoptosis, and the immune response and vision [1-3]. Retinoic acid (RA) also plays a role in protecting the intestinal barrier, and cellular RA bioavailability has been shown to determine epithelial integrity [4]. Additionally, VA improves intestinal epithelial cell migration and proliferation and prevents Clostridium difficile toxin A challenge-induced reductions in transepithelial resistance (TER) [5]. Our previous studies showed that VA deficiency (VAD) during pregnancy suppresses the systemic and mucosal immune responses in the intestines of offspring by decreasing lymphocyte counts [6]. Moreover, VA supplementation (VAS) during early life can improve immune cell counts to enhance the intestinal immune responses of rats [7]. Additionally, VA can regulate intestinal mucosal immunity and homeostasis [8] and can also improve intestinal barrier function [9]. The results of a previous metaanalysis suggested that VA treatment decreased the incidence of and the risk of mortality from diarrhoea in children in developing countries [10]. VA also plays an important role in epithelial function; however, how VA regulates intestinal barrier function, as well as which RA receptors (RARs) regulate the protective effects of VA on the intestinal epithelial cell monolayer, remains unknown.

Toll-like receptors (TLRs), which have been linked to innate and adaptive immunity, can trigger intestinal epithelial cell proliferation when the intestinal barrier is damaged [11]. As the major receptor associated with lipopolysaccharide activation, TLR4, along with other TLRs, maintains mucosal homeostasis in the intestine. TLR4/MD-2 expression is upregulated in inflammatory bowel disease (IBD) [12,13], and TLR4 and MyD88 signalling are required to optimize cell proliferation and protect against apoptosis in intestinal injury [14, 15]. Tight junctions (TJs) are the apical-most intercellular epithelial cell structures and contain many proteins, such as occludins, zonula occludens (ZOs) and actin [16, 17]. TJs maintain intestinal epithelial barrier integrity, and their destruction results in disruption of the intestinal environment. ZO proteins are cytosolic scaffolds that anchor peripherally located transmembrane proteins to the actin cytoskeleton, and their absence completely abrogates TJ assembly and paracellular regulation $[18,19]$. Therefore, ZO proteins are crucial for both barrier integrity and TJ formation. TLRs exert critical protective effects on TJs through a variety of pathways. For example, TLR2 enhances ZO-1-mediated intestinal epithelial barrier integrity via protein kinase C [20], and polyamine-induced TLR2 expression enhances epithelial barrier function [21]. Interestingly, VAD interferes with gastrointestinal mucosal 
barrier integrity by altering bacterial populations and innate immunity-related gene expression, and modulating TLR2 expression [8]. However, the data substantiating the idea that VA can regulate TJ proteins through TLRs in the intestinal epithelium are limited.

To address these issues, we focused on VA and the mechanisms by which it regulates colonic innate barrier function through the RAR pathway. First, we determined the optimum concentration of RA to which the Caco-2 cell line, a human colon carcinoma cell line that simulates the intestinal epithelial monolayer [22], responds to identify the proteins targeted by RA to regulate barrier function. Second, we established rat models of VAD and VAS to confirm that changes in RAR $\beta$, TLR4 and ZO-2 expression levels occur following decreases or increases in retinol concentration in vivo. VA normal (VAN) rats served as controls. Third, we altered RAR $\beta$ signalling in Caco- 2 cells to determine the regulatory effects of RAR $\beta$ on TLR4 and ZO-2 expression levels. Fourth, we used a siTLR4 lentivirus and TLR4 knockout mice to determine whether TLR4 is necessary for the protective effects of VA on the intestinal epithelium in vitro and in vivo. Finally, we assessed the interactions among the three proteins mentioned above using immunoprecipitation.

\section{Materials and Methods}

\section{Cell culture}

Caco- 2 cells were obtained from the Shanghai Institute for Biological Sciences, Chinese Academy of Science (Shanghai, China). Caco-2 cells $\left(1 \times 10^{5}\right.$ cells $\left./ \mathrm{cm}^{2}\right)$ were incubated with Dulbecco's modified Eagle medium (DMEM) containing $10 \%$ foetal bovine serum (FBS) in a $5 \% \mathrm{CO}_{2}$ humidified incubator at $37{ }^{\circ} \mathrm{C}$. The Caco- 2 cells were washout after $3 \mathrm{~h}$ seeding, and they were confluent after 2-3 days. The Caco- 2 cells were differentiated following 8 days of confluency, and then the experiments were carried out. The cells were treated with all-trans retinoic acid (ATRA) (R2625, Sigma-Aldrich, St. Louis, MO) at five different concentrations $(0.5 \mu \mathrm{mol} / \mathrm{L}, 1 \mu \mathrm{mol} / \mathrm{L}, 5 \mu \mathrm{mol} / \mathrm{L}, 10 \mu \mathrm{mol} / \mathrm{L}$, and $20 \mu \mathrm{mol} / \mathrm{L})$ for 24 hours after reaching confluence. Untreated cells served as controls. The cells were infected with recombinant adenoviruses carrying RAR $\beta$ (Ad-RAR $\beta$ ) and a small-interfering RNA targeting RAR $\beta$ (siRAR $\beta$ ) for 48 hours, as described previously [23]. An adenovirus containing red fluorescent protein (Ad-RFP) was used as a control. All three viruses were utilized under similar interference conditions. A rat siTLR4 lentivirus containing RFP was used to knockdown TLR4 in Caco-2 cells for 48 hours, and a lentivirus containing RFP served as a control. These viruses were utilized under similar interference conditions. The sequences of the siRAR $\beta$, RFP, siTLR4, and RFP constructs are listed in Table 1. Each group of cells was treated at the same stage.

\section{Animals}

The animal experiments were approved by the Animal Experimentation Ethics Committee of Chongqing Medical University (Chongqing, China) and were conducted in accordance with the guidelines of the Animal Care Committee of Chongqing Medical University. All the animals were housed under specific pathogen-free (SPF) laboratory conditions. Sprague Dawley (SD) rats were purchased from the Center of Zoology of Chongqing Medical University [certificate: SCXK (Yu) 2007-0001, Chongqing, China], and TLR4/- and wild-type(WT) mice derived from Jackson laboratories (Maine, USA) were purchased from the Model Animal Research Center of Nanjing University (MARC). The VAN and VAD animal models were constructed according to the methods described previously [7, 24, 25]. Maternal VAD rats were fed a VAD-inducing diet comprising $400 \mathrm{IU} / \mathrm{kg}$ VA for 4 weeks to establish the VAD animal model before gestation, whereas VAN rats received a VAN diet containing 6,500 IU/kg VA to serve as a control group. When serum retinol levels, which were measured using blood samples taken from the tails of the maternal VAD rats, decreased to $1.05 \mu \mathrm{mol} / \mathrm{L}$,

Table 1. Sequences of the interfering RNAs

\begin{tabular}{lll}
\hline No. & Name & Sequences \\
\hline 1 & siRAR $\beta$ & $\begin{array}{l}\text { aGCATTGAGAAGAACATGATtt } \\
\text { aATCATGTTCTTCTCAATGCttt }\end{array}$ \\
2 & RFP & $\begin{array}{l}\text { aTCAACAAGGTCACCAGAAAtttt } \\
\text { aTTTCTGGTGACCTTGTTGAttt }\end{array}$ \\
3 & siTLR4 & $\begin{array}{l}\text { CCTTTCCGGGACTTTCGCTTT } \\
\text { GCAGAATCCAGGTGGCAACA }\end{array}$ \\
4 & GFP & $\begin{array}{l}\text { CCTTTCCGGGACTTTCGCTTT } \\
\text { GCAGAATCCAGGTGGCAACA }\end{array}$ \\
\hline
\end{tabular}




\section{Cellular Physiology Cell Physiol Biochem 2017;42:1390-1406 \begin{tabular}{l|l} 
DOI: 10.1159/000479203 & $\begin{array}{l}\text { O 2017 The Author(s). Published by S. Karger AG, Basel } \\
\text { www.karger.com/cpb }\end{array}$
\end{tabular}}

Li et al.: RAR $\beta$ Regulates TLR4 to Improve Barrier Function

the maternal VAD rats were mated with normal male rats. Pregnant maternal rats were fed either the VAD diet or the VAN diet during both gestation and lactation to maintain stable serum retinol levels. After weaning, the pups from the VAD group were randomly assigned to the VAD and VAS groups. The pups in the VAD group were subsequently fed the VAD diet continuously for 6 weeks, while the pups in the VAN group were fed the VAN diet continuously for the same time period. The VAS group was subjected to the following treatments: lactating maternal VAD rats were fed the VAN diet until the weaning period, and the pups of gestational VAD rats were intragastrically administered 50 IU of VA daily for 7 days and fed the VAN diet for 6 weeks after weaning.

\section{Serum retinol detection}

Serum retinol concentrations were determined by high performance liquid chromatography (HPLC), according to a method described previously [24]. Briefly, $200 \mu \mathrm{L}$ of serum was deproteinized with dehydrated alcohol, and then the retinol was extracted with hexane and evaporated with nitrogen gas. The residue was dissolved in $100 \mu \mathrm{L}$ of the indicated mobile phase mixture (methanol:water ratio of 97:3), after which the entire sample was transferred to a bottle incorporated into the HPLC apparatus (DGU-20 As, Shimadzu Corporation, Kyoto, Japan). The retinoids were separated by chromatography on an analytical column (Hypersil phenyl 120 A 5 mm, 250×4.6 mm, Phenomenex, USA) via gradient elution of the mobile phase in a liquid chromatograph equipped with a 315-nm ultraviolet photodiode array detector.

\section{Enzyme-linked immunosorbent assay (ELISA)}

The levels of zonulin release in the culture media of the different treatment groups were measured by a human zonulin ELISA kit (Hermes Criterion Biotechnology), according to the manufacturer's instructions. Background values, which served as control values, were also analysed. The absorbance was measured at a wavelength of $450 \mathrm{~nm}$, and the optical density values were calculated based on standard curves constructed for each of the assays, which were performed in triplicate.

\section{TER}

Caco- 2 cells were seeded $\left(1 \times 10^{5}\right.$ cells $\left./ \mathrm{cm}^{2}\right)$ in a transwell chamber with $0.4-\mu \mathrm{m}$ pores (PIHT $12 \mathrm{R} 48$, Merk Millipore) that had been placed in a 24 -well plate. The other two transwells remained blank. After being confluent, cells were differentiated and polarized for 14 days in the culture medium with or without ATRA treatment. The TER of the monolayer was measured with a Millicell Electrical Resistance System-2 (Merk Millipore), according to the manufacturer's protocol [26]. We corrected the TER values by subtracting the background resistance of the blank membranes and then multiplied the values by the area of the transwell. Three independent experiments were performed.

The TER of the intestinal epithelial barrier was determined with an Ussing Chamber and Voltage/ Current ClampSystem (Physiology Instruments, SanDiego, USA). After being stripped from the muscular layer using an anatomical microscope, the colon mucosal tissue layer was fixed on the Ussing Chamber and bathed on both its serosal and mucosal sides with Krebs-Ringer solution. The bathing solutions were oxygenated $\left(95 \% \mathrm{O}_{2} / 5 \% \mathrm{CO}_{2}\right)$ and circulated in water-jacketed reservoirs at $37{ }^{\circ} \mathrm{C}$ [27]. After equilibrating in the Ussing chambers for 20 minutes, the cells were subjected to the experiments for up to 1.5 hours. TER was calculated using the data from the different short-circuit currents. Data acquisition and analysis were performed using Acquire \& Analyse software.

\section{RNA extraction and real-time polymerase chain reaction (PCR)}

Total RNA from the animal colonic mucosal layer cells and Caco-2 cells was isolated and purified using an RNA extraction kit (RP1202, BioTeke, Beijing, China). The mRNA was then reverse transcribed into first-strand cDNA using a PrimeScript RT Reagent Kit (DRR036A, Takara Bio, Inc.). Real-time PCR reactions were performed using a Real Master Mix Kit (RR820A, Takara Bio, Inc.) and a real-time PCR instrument (CFX Connect Real-Time System, Bio-Rad). Each sample was quantified in triplicate. Gene expression levels were normalized to $\beta$-actin expression levels in the same samples and were calculated using CFX Manager Software. Three independent experiments were performed, and each experiment was performed in duplicate. The sequences of the primers specific for RAR $\alpha$, RAR $\beta$, RAR $\gamma$, TLR2, TLR4, occludin, ZO-1, ZO-2 and $\beta$-actin in the corresponding species were designed using Primer Premier 5 software and are listed in Tables 2 and 3. 


\begin{tabular}{|c|c|c|}
\hline Cellular P & Cell Physiol Biochem 2017 & 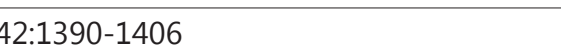 \\
\hline and Biochemistry & $\begin{array}{l}\text { DOI: 10.1159/000479203 } \\
\text { Published online: July 17, } 2017\end{array}$ & $\begin{array}{l}\text { O } 2017 \text { The Author(s). Published by S. Karger AG, Basel } \\
\text { www.karger.com/cpb }\end{array}$ \\
\hline
\end{tabular}

Western blotting

Total proteins were extracted from the animal colonic epithelial cell monolayer and Caco-2 cells using a specific extraction kit (PP1901, BioTeke), and the protein concentrations in the homogenates were determined with a Micro BCA Protein Assay Kit (P1001, BioTeke) using an enzyme-labelling instrument (Thermo Scientific Varioskan Flash). Approximately $30 \mu \mathrm{g}$ total protein per lane was loaded onto a 10\% SDS-polyacrylamide gel (Beyotime, Haimen, China) for electrophoretic separation, after which the proteins were transferred to polyvinylidene fluoride membranes (HATF00010, Merk Millipore), which were blocked with $5 \%$ bovine serum albumin (BSA) in TBS containing $0.5 \%$ Tween for $1 \mathrm{~h}$ at $37{ }^{\circ} \mathrm{C}$ and then probed with anti-RAR $\beta$ (ab53161, Abcam), anti-TLR4 (ab22048, Abcam), anti-ZO-2 (2847, Cell Signaling Technology) or anti- $\beta$-actin (sc-47778, Santa) primary antibodies over night at $4{ }^{\circ} \mathrm{C}$. The proteins were subsequently probed with HRP-conjugated secondary antibodies (Santa Cruz Biotechnology) for 1 hour at room temperature and visualized on an ECL Imaging System (SynGene GBOX) using a chemiluminescence kit (1229601, Merk Millipore). Three independent experiments were performed.

\section{Co-immunoprecipitation}

The total protein extracts from the Caco-2 cell line were prepared using the appropriate kits (PP1801, BioTeke), and the protein concentrations were determined as described above. For immunoprecipitation analysis, $300 \mu \mathrm{g}$ of total protein extract was incubated with $0.2-2 \mu$ g of anti-RAR $\beta$ (sc-552G, Santa), antiZO-2 (sc-8148, Santa) or control IgG antibodies and protein-G agarose beads (Beyotime) overnight at $4{ }^{\circ} \mathrm{C}$. After being washed three times, the immunoprecipitates were boiled and then assessed by western blotting. Three independent experiments were performed.

\section{Immunofluorescence staining}

Confluent Caco-2 cells were cultured on $1 \times 1-\mathrm{cm}$ cover slips, fixed with a mixture of methanol and glacial acetic acid (ratio of 3:1) for 20 minutes at $4{ }^{\circ} \mathrm{C}$ and then washed three times with phosphate-buffered saline (PBS). The fixed cells were subsequently incubated in PBS containing 0.2\% Triton X-100 and blocked with 5\% BSA for 1 hour at room temperature. The cells were then incubated with anti-RAR $\beta$ (ab53161, Abcam),
Table 2. Sequences of the primers specific for the human or mouse genes

\begin{tabular}{|c|c|c|}
\hline No. & Name & Sequences \\
\hline 1 & RAR $\alpha$ & $\begin{array}{l}\text { TCCGCCGCAGCATCCAGAAGAACAT } \\
\text { ACTCGGGCTTGGGCACCTCCTTCTT }\end{array}$ \\
\hline 2 & RAR $\beta$ & $\begin{array}{l}\text { GGAACACAGCAGAGCACAG } \\
\text { ACGAGTGGTGACTGACTGAC }\end{array}$ \\
\hline 3 & $\mathrm{RAR} \gamma$ & $\begin{array}{l}\text { CGCCGAAGCATCCAGAAGAAC } \\
\text { GCGATTCCTGGTCACCTTGTTG }\end{array}$ \\
\hline 4 & TLR2 & $\begin{array}{l}\text { GATGCCTCCCTCTTACCC } \\
\text { CCAGTGCTTGCTGCTCCT }\end{array}$ \\
\hline 5 & TLR4 & $\begin{array}{l}\text { AGACCTGTCCCTGAACCCTAT } \\
\text { CTAAACCAGCCAGACCTTGA }\end{array}$ \\
\hline 6 & $\mathrm{ZO}-1$ & $\begin{array}{l}\text { GGATGTTTATCGTCGCATTGTAGAA } \\
\text { AATAGCAAGCCAAGAGCCCAGTTTT }\end{array}$ \\
\hline 7 & $\mathrm{ZO}-2$ & $\begin{array}{l}\text { CTGGTGGCAATGATGTCG } \\
\text { CCCGCACTAATCCTCTGAAA }\end{array}$ \\
\hline 8 & Actin & $\begin{array}{l}\text { GTGAAGGTGACAGCAGTCGGTT } \\
\text { GAGAAGTGGGGTGGCTTTTAGGA }\end{array}$ \\
\hline
\end{tabular}

Table 3. Sequences of the primers specific for the rat genes

\begin{tabular}{lll}
\hline No. & Name & Sequences \\
\hline 1 & RAR $\beta$ & $\begin{array}{l}\text { AAAGCCACCAGGAAACC } \\
\text { CTTGGCGAACTCCACGAT }\end{array}$ \\
2 & TLR4 & $\begin{array}{l}\text { TAGCCGCTCTGGCATCAT } \\
\text { GCATTGTCCTCCCACTCG }\end{array}$ \\
3 & Z0-2 & $\begin{array}{l}\text { AGAAGAACATTCGCAAGAGC } \\
\text { TTTGAAACAGGTCGGGTAG }\end{array}$ \\
4 & GAPDH & $\begin{array}{l}\text { CCTGGAGAAACCTGCAAG } \\
\end{array}$ \\
& & CACAGGAGACAACCTGGTCC \\
\hline
\end{tabular}

Table 4. Sequences of the primers specific for the promoters

\begin{tabular}{lll}
\hline No. & Name & Sequences \\
\hline 1 & RAR $\beta$ & $\begin{array}{l}\text { GGAAGTGAGCTGTTCAGAGGCAG } \\
\text { GGCATCCCAGTCCTCAAAC }\end{array}$ \\
2 & TLR4 & $\begin{array}{l}\text { CACACTTGCTGACACCTTGAG } \\
\text { GGCTGCCATAAGGAAATACCAC }\end{array}$ \\
3 & ZO-2 & $\begin{array}{l}\text { CTGTGTGAGGCCCTGCGAAC } \\
\text { GTTTGGAGACCTGGAGTGAG }\end{array}$ \\
\hline
\end{tabular}
anti-TLR4 (sc-13593, Santa) or anti-ZO-2 (sc-8148, Santa) antibodies overnight at $4{ }^{\circ} \mathrm{C}$. The cells were subsequently washed and incubated with anti-rabbit IgG, anti-mouse IgG or anti-goat IgG (Invitrogen) for 1 hour, after which the nuclei were stained with 4', 6-diamidino-2-phenylindole (DAPI; Sigma) for 10 minutes at room temperature in a dark room. Fluorescence images were captured with an immunofluorescence laser confocal microscope (Nikon). Control IgGs were used as negative controls. Three independent experiments were performed.

Chromatin immunoprecipitation (ChIP)

Samples were prepared using a ChIP kit (17-371, Merk Millipore), according to the manufacturer's protocols. Caco- 2 cells were treated with $1 \%$ formaldehyde to crosslink the proteins of interest to the DNA sequences of interest. The cells were prepared with SDS lysis buffer and then sonicated with a Bioruptor UCD-200 (Diagenode), after which the DNA was sheared into 200-1,000-bp fragments. Equal amounts (100 
$\mu \mathrm{l})$ of DNA/protein complex were assayed and diluted to the indicated volume ( $900 \mu \mathrm{l})$ with ChIP dilution buffer. Before IP, $10 \mu \mathrm{l}$ of supernatant from each sample was designated as the 'total input chromatin', and the remaining supernatant was incubated with 1-10 $\mu \mathrm{g}$ of primary antibodies against RAR $\beta$ (sc-552X, Santa) or negative control IgG antibodies overnight at $4{ }^{\circ} \mathrm{C}$. DNA reverse-crosslinking and purification were performed according to the manufacturer's protocols, and semiquantitative PCR amplification was performed as described in the real-time PCR section. The primers used for promoter amplification are listed in Table 4.

\section{Statistical analysis}

All the data are expressed as the mean \pm SEM. The differences between groups were analysed with one-way analysis of variance (ANOVA) and t-tests using GraphPad Prism software, version 5.0. $P<0.05$ was considered statistically significant.

\section{Results}

\section{RA enhanced the Caco-2 cell monolayer}

The usefulness of the Caco- 2 cell line in vitro models of intestinal epithelial permeability has been established previously. The above cells were treated with ATRA(a major active cellular retinoid metabolite) at five different concentrations $(0.5 \mu \mathrm{mol} / \mathrm{L}, 1 \mu \mathrm{mol} / \mathrm{L}, 5 \mu \mathrm{mol} / \mathrm{L}$, $10 \mu \mathrm{mol} / \mathrm{L}$, and $20 \mu \mathrm{mol} / \mathrm{L}$ ) for 24 hours (Steffen Baltes), after which they were examined under a microscope and found to be more tightly arranged as a monolayer than untreated cells. As shown in Fig. 1A, ATRA-treated cells were closer to one another than untreated cells, and the junctions between them were brighter and thicker than those between untreated cells. The TER of the Caco- 2 cell monolayer was subsequently detected with a digital voltageresistance metre. TER is a sensitive indicator of and is inversely proportional to epithelial barrier permeability [28]. The TER of the Caco-2 cell monolayer was $275.1 \pm 14.69 \Omega . \mathrm{cm}^{2}$ in the group of cells treated with $5 \mu \mathrm{mol} / \mathrm{L}$ ATRA, a value that was 2.13 times greater $(P=0.0003$, t test $)$ than that in the untreated control group $\left(128.8 \pm 12.75 \Omega . \mathrm{cm}^{2}\right.$; Fig. 1B). Zonulin is a physiologic regulatory protein that reflects intestinal permeability [29]. Alessio Fasano and his colleagues [7] found that small intestines exposed to enteric bacteria secreted zonulin, which resulted in increases in intestinal permeability. The relationship between

Fig. 1. ATRA enhanced the Caco-2 cell monolayer. The control group was not treated with ATRA. (A) The changes in the tightness of the Caco2 cell barrier elicited by treatment with five different concentrations of ATRA for 24 hrs, as determined by morphological observation(original magnification $\times 200$ ). (B) Caco-2 cell TER was increased by treatment with $5 \mu \mathrm{mol} / \mathrm{L}$ ATRA compared with no treatment. The values were obtained from three independent experiments. (C) Zonulin release was detected in the media of Caco- 2 cells treated with or without ATRA (5 $\mu \mathrm{mol} / \mathrm{L}$ ) via ELISA. The values represent the mean \pm SD for more than three different samples. ${ }^{* *} P<0.01$ and ${ }^{* * *} P<0.001$ versus the control group.

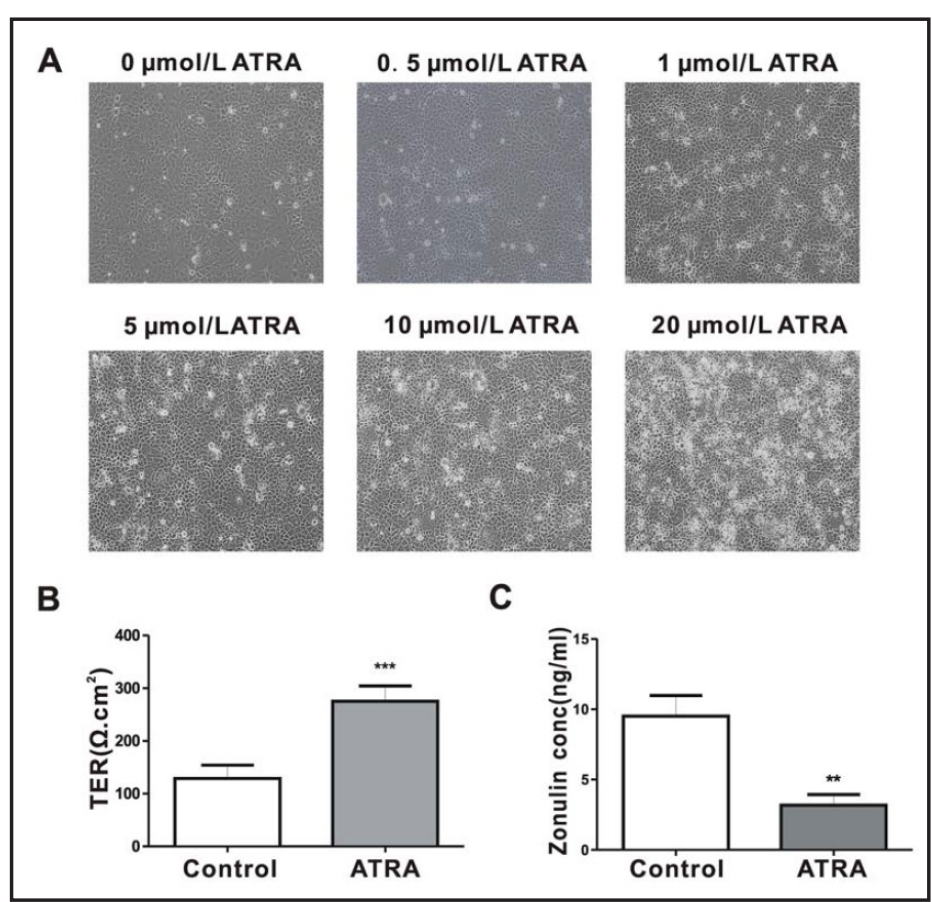




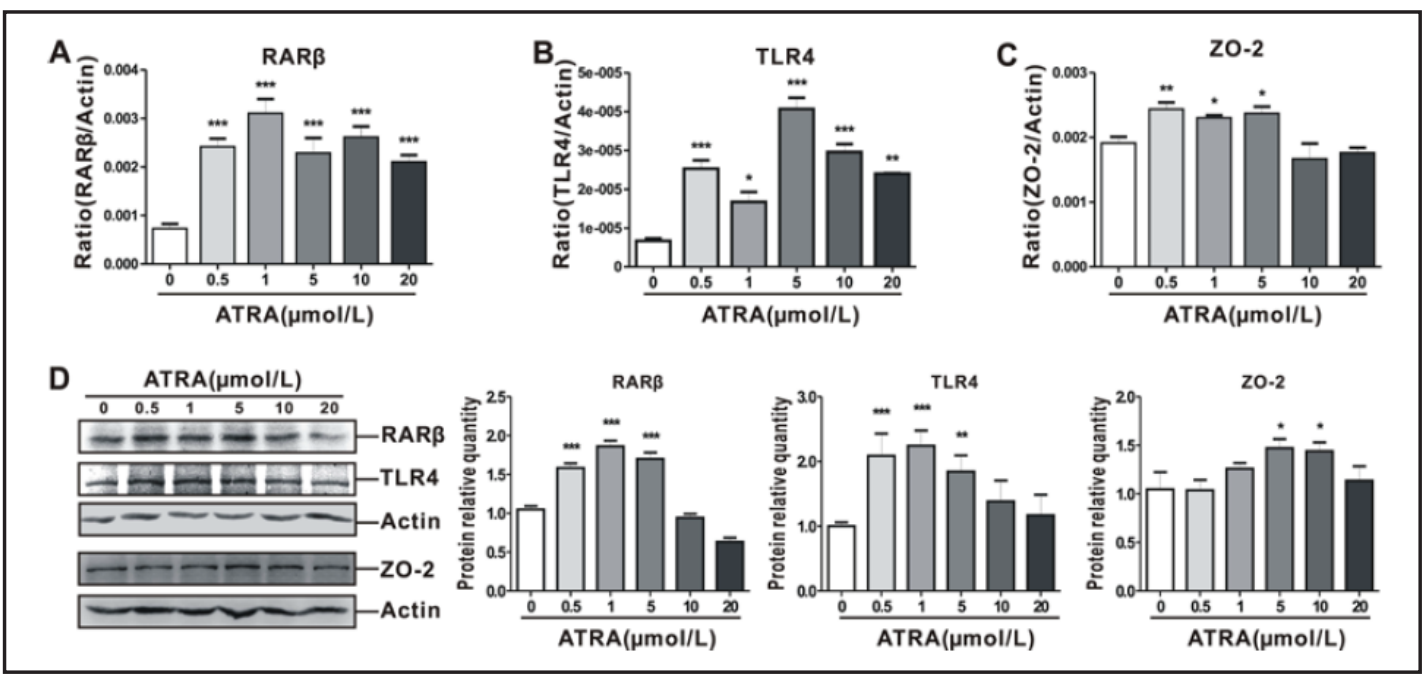

Fig. 2. ATRA enhanced RAR $\beta$, TLR 4 and ZO- 2 mRNA and protein expression in Caco-2 cells. RAR $\beta$ (A), TLR4 (B) and ZO-2 (C) mRNA expression levels were detected by qPCR and normalized to $\beta$-actin expression levels. The data are representative of three independent experiments and expressed as the mean \pm SEM. ${ }^{*} P<0.05,{ }^{* *} P<0.01,{ }^{* * *} P<0.001$ versus the $0 \mu \mathrm{mol} / \mathrm{L}$ ATRA group. (D) RAR $\beta$, TLR 4 and ZO-2 protein expression levels were determined by western blotting.

zonulin secretion and intestinal permeability is direct; thus, the higher the level of zonulin secreted, the larger the increase in intestinal permeability. As shown in Fig. 1C, the zonulin concentration $(3.164 \pm 0.7723 \mathrm{ng} / \mathrm{mL})$ in the Caco-2 culture medium of the ATRA ( $5 \mu \mathrm{mol} / \mathrm{L})$ group was significantly lower $(P=0.01, \mathrm{t}$ test $)$ than that in culture medium of the control group $(9.506 \pm 1.481 \mathrm{ng} / \mathrm{mL})$. These data demonstrate that ATRA treatment enhances Caco-2 cells to maintain a tight barrier, thereby decreasing barrier permeability.

\section{ATRA induced RAR $\beta$, TLR4 and ZO-2 expression in Caco-2 cells}

RA plays an essential role in biological processes by binding to its receptors, namely, RAR $\alpha$, RAR $\beta$ and RAR $\gamma$. ATRA exerts its biological effects at physiological doses. In the current study, to better understand the regulatory mechanism through which ATRA exerts its effects, we administered ATRA at 'pharmacological' concentrations as a treatment. We analysed RARs mRNA expression levels in cells treated with different concentrations of ATRA for 24 hours by qPCR. We found that RAR $\beta$ mRNA levels but not RAR $\alpha$ and RAR $\gamma$ levels increased in ATRA-treated cells compared with control cells (data not shown). Fig. 2A shows that RAR $\beta$ expression levels were low without ATRA treatment; however, treatment with $0.5-20 \mu \mathrm{mol} / \mathrm{L}$ ATRA significantly up-regulated RAR $\beta$ expression levels $(P<0.0001$, ANOVA), which peaked in response to treatment with $1 \mu \mathrm{mol} / \mathrm{L}$ ATRA and then decreased in response to treatment with high concentrations of ATRA $(20 \mu \mathrm{mol} / \mathrm{L})$, indicating that high pharmacological concentrations of ATRA may be toxic to Caco- 2 cells. Taken together, these results suggest that the RAR $\beta$ pathway may be regulated by ATRA in Caco- 2 cells.

TLRs are expressed in a variety of cells and link innate and acquired immunity. TLR2 and TLR4 are expressed in human colon tissues; however, the expression levels of these proteins are very low in human colon tissues [12, 30, 31]. Caco-2 cells are a human colon intestinal epithelial cell line in which multiple TLRs can be detected. In the present study, we analysed TLR2 and TLR4 mRNA expression levels by qPCR, and found that TLR4 expression levels were increased $(P<0.0001$, ANOVA) by treatment with ATRA for 24 hours compared with no treatment and peaked in response to treatment with $5 \mu \mathrm{mol} / \mathrm{L}$ ATRA (Fig. 2B). However, we noted no significant differences in TLR2 mRNA expression levels between treated and untreated cells (data not shown). These data indicate that the TLR4 pathway may be related to the RA pathway in Caco-2 cells.

\section{KARGER}


A

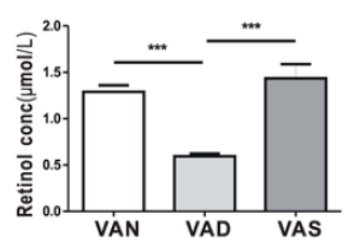

C

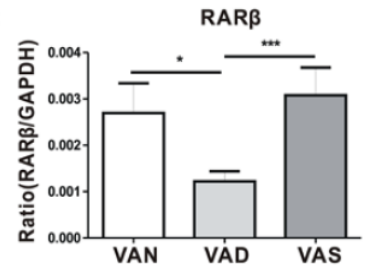

D

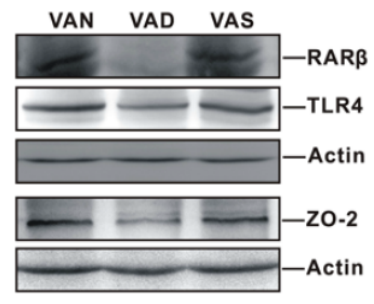

B
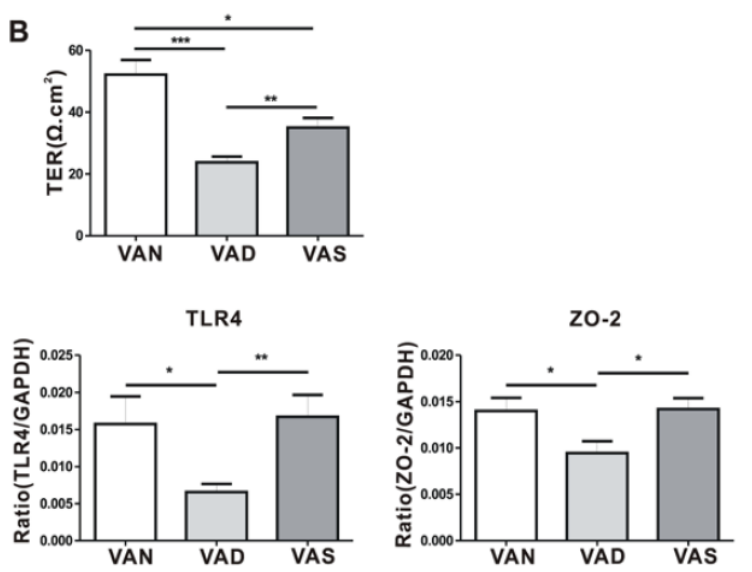

Fig. 3. Vitamin A (VA) deficiency decreased TER and RAR $\beta$, TLR4, and ZO-2 expression levels in the colon monolayer of the rat model. VAN refers to VA normal, VAD refers to VA deficiency, and VAS refers to VA supplementation. (A) The serum VA levels of six-week-old rats in the VAN( $\left.n_{\mathrm{VAN}}=14\right), \operatorname{VAD}\left(\mathrm{n}_{\mathrm{VAD}}=14\right)$ and VAS ( $\left.\mathrm{n}_{\mathrm{VAS}}=10\right)$ groups were tested by HPLC. ${ }^{* * *} P<0.001$. (B) A Ussing chamber was used to measure the differences in TER among the VAN $\left(\mathrm{n}_{\mathrm{VAN}}=9\right)$, VAD $\left(\mathrm{n}_{\mathrm{VAD}}=11\right)$ and VAS $\left(\mathrm{n}_{\mathrm{VAS}}=6\right)$ groups. ${ }^{*} P<0.05,{ }^{* *} P<0.01$, *** $P<0.001$. (C) The mRNA expression levels of RAR $\beta$, TLR4 and ZO-2 in the colon monolayers of the VAN $\left(\mathrm{n}_{\mathrm{VAN}}=5\right), \mathrm{VAD}\left(\mathrm{n}_{\mathrm{VAD}}=5\right)$, and VAS $\left(\mathrm{n}_{\mathrm{VAS}}=4\right)$ groups. ${ }^{*} P<0.05,{ }^{* *} P<0.01,{ }^{* * *} P<0.001$. (D) RAR $\beta$, TLR4 and ZO-2 protein expression levels were detected in the colons of the VAN ( $\left.\mathrm{n}_{\mathrm{VAN}}=5\right), \operatorname{VAD}\left(\mathrm{n}_{\mathrm{VAD}}=5\right)$ and VAS $\left(\mathrm{n}_{\mathrm{VAS}}=4\right)$ groups. The data are representative of three independent experiments.

As shown in Fig. 2C, ZO-2 mRNA expression levels were significantly increased $(P=0.0001$, ANOVA $)$ in cells treated with ATRA for 24 hours compared with untreated cells, while occludin and ZO-1 mRNA expression levels in ATRA-treated cells were not significantly different compared from those in control cells (data not shown). We also found that RAR $\beta$, TLR4 and ZO-2 protein expression levels were enhanced by treatment with ATRA at different concentrations compared with no treatment (Fig. 2D), results consistent with those of the experiments in which the mRNA expression levels of the indicated proteins were determined. The above results suggest that the TLR4 and ZO-2 proteins may help ATRA induce Caco-2 cell rearrangements via the RAR $\beta$ pathway.

VAD decreased TER and RAR $\beta, T L R 4$, and ZO-2 expression levels in rat colon mucosal cell layers

To evaluate the effects of VA on intestinal epithelial barrier function, we established VAD and VAS rat models in the current study. Fig. 3A shows that serum retinol levels in sixweek-old VAD rats were significantly lower $\left(\mathrm{n}_{\mathrm{VAD}}=14, \mathrm{n}_{\mathrm{VAN}}=14, P<0.0001\right.$, $\mathrm{t}$ test $)$ than those in VAN rats of the same age, suggesting that the VAD rat model was successfully established. Serum retinol levels increased significantly in VAD pups that received VA supplementation beginning on postnatal day 1 compared with VAD pups that did not receiving supplementation $\left(\mathrm{n}_{\mathrm{VAS}}=10, \mathrm{n}_{\mathrm{VAD}}=14, P<0.0001, \mathrm{t}\right.$ test $)$. Additionally, we noted no significant difference $(P=0.3564, \mathrm{t}$ test $)$ in serum retinol levels between the VAN and VAS groups. 
Fig. 4. RAR $\beta$, TLR4 and ZO-2 expression levels in Caco- 2 cells after the cells were infected by Ad-RAR $\beta$ or siRAR $\beta$ in the presence or absence of ATRA. (A-C) RAR $\beta$, TLR4 and ZO-2 mRNA expression levels were significantly up-regulated by recombinant Ad-RAR $\beta$ infection. ${ }^{* * *} P<0.001$ versus Ad-RFP group. Ad-RFP was the control for the Ad-RAR $\beta$ recombinant adenovirus. (D) Changes in RAR $\beta$, TLR4 and ZO-2 protein expression levels in Caco- 2 cells infected with AdRAR $\beta$. (E) RAR $\beta$, TLR4 and ZO-2 protein expression levels were suppressed by siRAR $\beta$ adenoviruses in Caco- 2 cells. (F) Changes in RAR $\beta$, TLR4 and ZO-2 protein expression levels in Caco-2 cells following siRAR $\beta$ infection and ATRA treatment. Three independent experiments were performed.

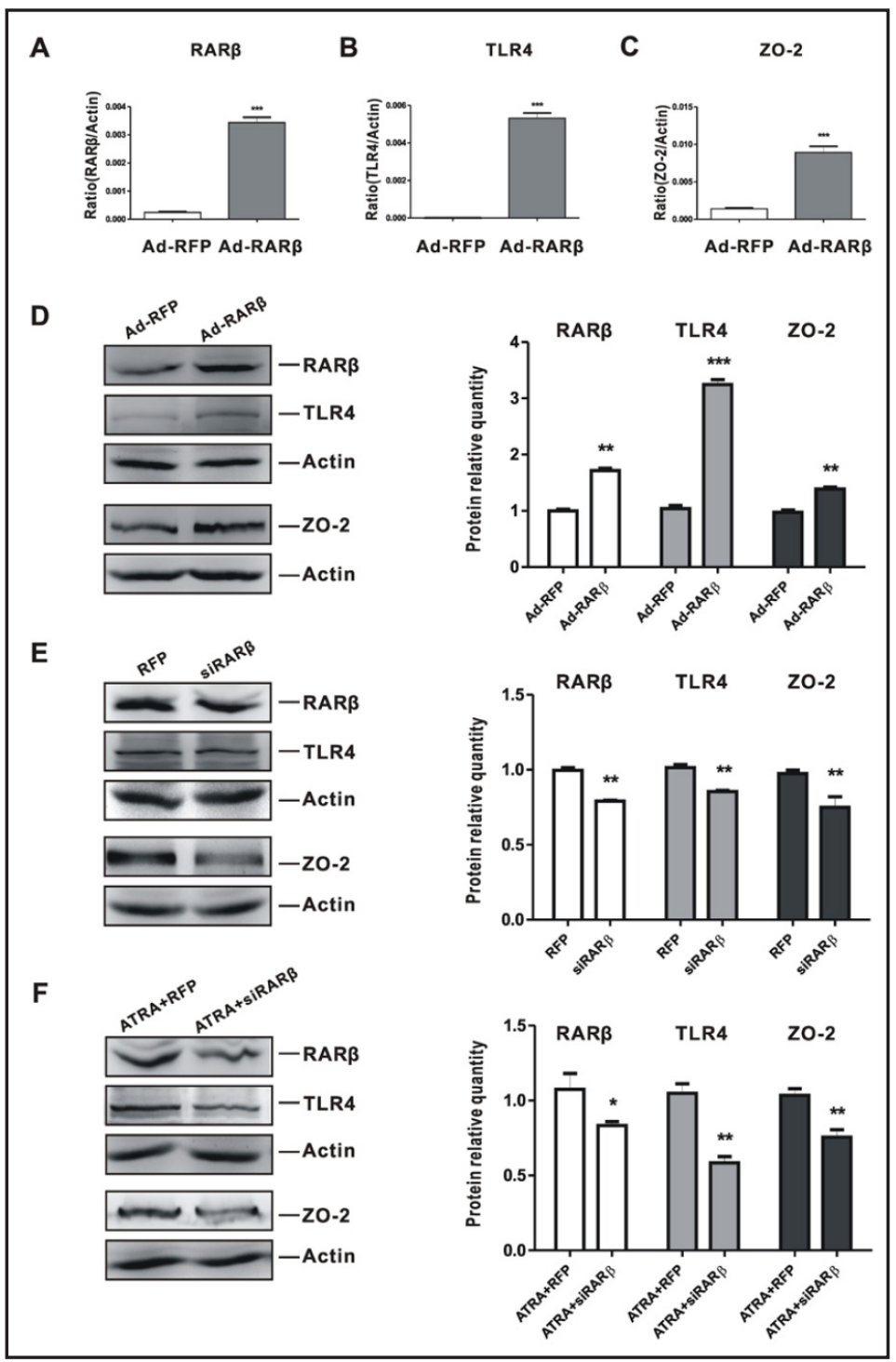

We measured the TER of the rat colonic monolayer with an Ussing Chamber and found that the TER of the VAD group was $23.75 \pm 1.877 \Omega . \mathrm{cm}^{2}$, a value was significantly lower $\left(\mathrm{n}_{\mathrm{VAD}}=11, \mathrm{n}_{\mathrm{VAN}}=9, P<0.001, \mathrm{t}\right.$ test) than that of the VAN group $\left(52.18 \pm 4.759 \Omega . \mathrm{cm}^{2}\right)$. Additionally, the TER in the VAS group $\left(35 \pm 3.141 \Omega . \mathrm{cm}^{2}\right)$ was significantly higher $\left(\mathrm{n}_{\mathrm{VAS}}=6\right.$, $P=0.0050$, t test) than that in the VAD group but was still decreased compared with that in the VAN group ( $P=0.019$, t test; Fig. 3B).

Moreover, we also assessed the changes in RAR $\beta$, TLR4 and ZO-2 mRNA and protein expression in the rat colonic monolayer. The results showed (Fig. 3C) that RAR $\beta$, TLR4 and ZO-2 mRNA expression levels were significantly reduced $\left(\mathrm{n}_{\mathrm{VAD}}=5, \mathrm{n}_{\mathrm{VAN}}=5, P_{\mathrm{RAR} \beta}=0.0138\right.$, $P_{\mathrm{TLR} 4}=0.0206, P_{\mathrm{ZO}-2}=0.0250, \mathrm{t}$ test) in the colon cell monolayer of the VAD group compared with that in the VAN group, while the expression levels of the three genes were significantly increased $\left(\mathrm{n}_{\mathrm{VAD}}=5, \mathrm{n}_{\mathrm{VAS}}=4, P_{\mathrm{RAR} \beta}=0.0008, P_{\mathrm{TLR} 4}=0.0078, P_{\mathrm{ZO}-2}=0.0199, \mathrm{t}\right.$ test $)$ in the VAS group compared with the VAD group. The trends in RAR $\beta$, TLR4 and ZO-2 protein expression were consistent with those in RAR $\beta$, TLR4 and ZO-2 mRNA expression (Fig. 3D). These results demonstrate that VA deficiency can decrease barrier function and RAR $\beta$, TLR4 and ZO-2 expression levels in the colonic cell monolayer and that timely VA intervention can effectively enhance RAR $\beta$, TLR4 and ZO-2 expression levels to improve intestinal barrier function. 
Fig. 5. RAR $\beta$, TLR4 and ZO-2 protein expression levels in Caco-2 cells following LvsiTLR4 infection in the presence and absence of ATRA. (A) RAR $\beta$, TLR4 and ZO-2 protein expression levels in Caco-2 cells infected with Lv-siTLR4. (B) RAR $\beta$, TLR4 and ZO-2 protein expression levels in Caco- 2 cells following Lv-siTLR4 infection and ATRA treatment. Three independent experiments were performed.

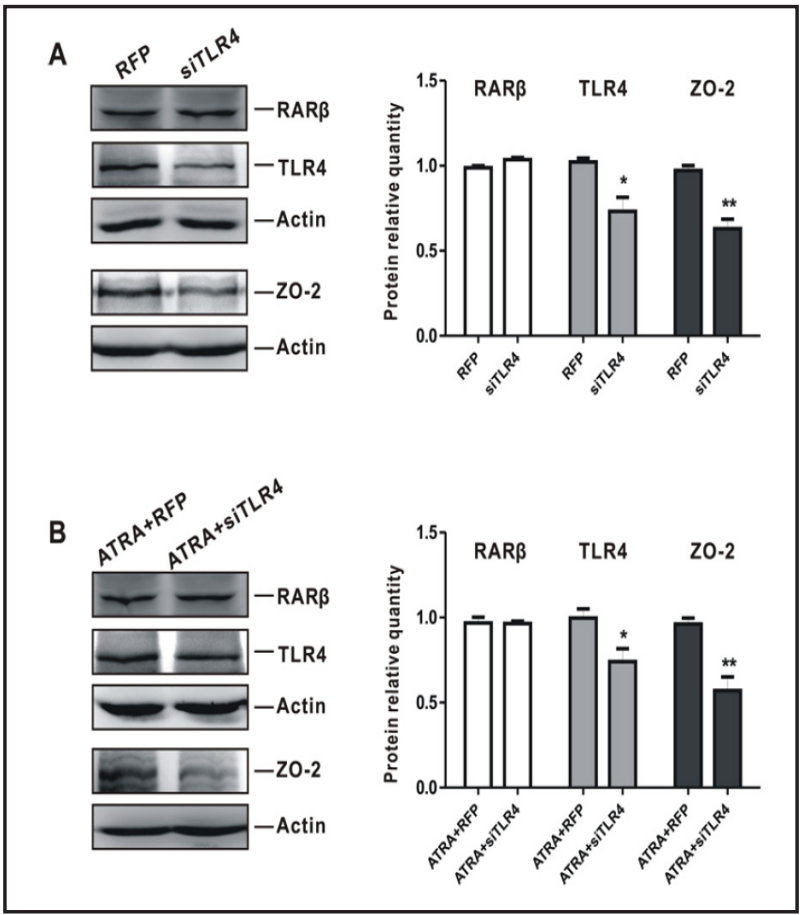

TLR4 and ZO-2 expression levels were regulated by Ad-RAR $\beta$ or siRAR $\beta$ in Caco- 2 cells

To determine whether TLR4 or ZO-2 expression levels were regulated by the RAR $\beta$ pathway, we altered RAR $\beta$ signalling in Caco- 2 cells using recombinant RAR $\beta$ or siRAR $\beta$ adenoviruses. First, we infected the cells with Ad-RAR $\beta$ and Ad-RFP. We found that RAR $\beta$ mRNA expression levels were significantly elevated ( $P=0.0017$, t test) in Caco-2 cells infected with Ad-RAR $\beta$ compared with cells infected with Ad-RFP (Fig. 4A) and that both TLR4 and ZO-2 mRNA expression levels were increased $\left(P_{\mathrm{TLR} 4}<0.0001, P_{\mathrm{zO}-2}<0.0001, \mathrm{t}\right.$ test $)$ in the former group of cells compared with the latter group of cells (Fig. 4B and 4C). After Ad-RAR $\beta$ infection, RAR $\beta$, TLR 4 and ZO-2 protein expression levels were also enhanced in the indicated group compared with the RFP group (Fig. 4D). These data demonstrate that the effects of RAR $\beta$ over-expression on Caco- 2 cells were consistent with those of ATRA treatment.

Second, we used siRAR $\beta$ adenoviruses to infect Caco- 2 cells. When siRAR $\beta$ knocked down RAR $\beta$ expression, as shown in Fig. 4E, TLR4 and ZO-2 protein expression levels were also suppressed in the corresponding group of Caco- 2 cells compared with the RFP-treated group of cells. Finally, we treated Caco- 2 cells with the combination of siRAR $\beta$ adenoviruses and ATRA, and found that both TLR4 and ZO-2 expression levels decreased in the indicated group compared with the ATRA+RFP group following the decrease in RAR $\beta$ expression levels (Fig. 4F). The above results show that ATRA regulates TLR4 and ZO-2 expression levels to enhance colon epithelial barrier function through the RAR $\beta$ pathway.

siTLR4 down-regulated ZO-2 expression levels but did not affect RAR $\beta$ expression levels in Caco-2 cells

We also hypothesized that TLR4 participates in the pathway modulated by RAR $\beta$. To confirm this hypothesis, we reduced TLR4 expression levels using a lentivirus containing TLR4-silencer sequences. As shown in Fig. 5A, the changes in TLR4 expression in the GFP and siTLR4 groups were consistent with the changes in ZO-2 expression but not RAR $\beta$ expression in the indicated groups (Fig. 5A). RAR $\beta$ protein expression levels increased after ATRA treatment; however, siTLR4 still reduced ZO-2 expression levels (Fig. 5B). These data demonstrate that TLR4 likely serves as an intermediary in the process by which RAR $\beta$ regulates ZO-2 expression in Caco-2 cells. 
Fig. 6. The differences in serum retinol levels, TER, and RAR $\beta$, TLR4 and ZO-2 expression levels in the colon monolayers of WT or TLR4\% mice between the VAN and VAD groups. WTVAN refers to WT mice with normal VA levels, WTVAD refers to WT mice with VA deficiency, KOVAN refers to TLR4 KO mice with normal VA levels, and KOVAD refers to KO mice with VA deficiency. (A) Serum retinol levels in six week-old mice in the WTVAN ( $\left.\mathrm{n}_{\text {WTVAN }}=9\right)$, WTVAD $\left(\mathrm{n}_{\text {WT- }}\right.$ $\left.{ }_{\text {VAD }}=7\right)$, KOVAN ( $\left.n_{\text {KOVAN }}=9\right)$ and KOVAD $\left(\mathrm{n}_{\text {KOVAD }}=11\right)$, groups were determined by HPLC. ${ }^{* *} P<0.01,{ }^{* * *} P<0.001$. (B) $\mathrm{A}$ Ussing chamber was used to measure the differences in TER among the four groups $\left(\mathrm{n}_{\text {WTVAN }}=9, \mathrm{n}_{\text {WTVAD }}=7, \mathrm{n}_{\text {KOVAN }}=9\right.$, $\mathrm{n}_{\text {KOVAD }}=11$ ). $\quad * * P<0.01$. (C-D) RAR $\beta$, TLR4 and ZO-2 mRNA expression levels were reduced in the colon monolayers of WTVAN, WTVAD, KOVAN, and KOVAD mice $(\mathrm{n}=5$ mice per group). ${ }^{*} P<0.05$, ${ }^{* *} P<0.01, \quad * * * P<0.001$. (E) RAR $\beta$, TLR4 and ZO-2 protein expression levels were detected in WT and KO mice with different serum retinol levels ( $n=5$ mice per group).
A
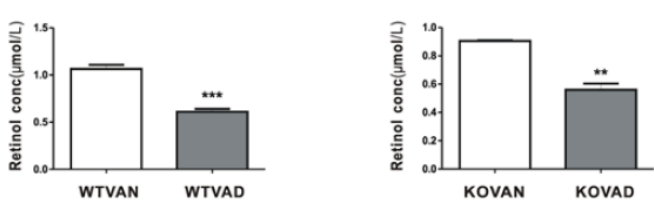

B

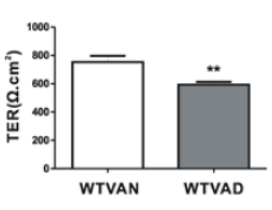

C

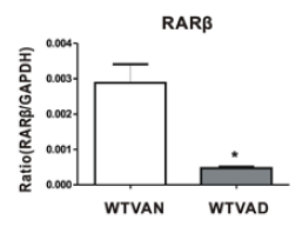

D

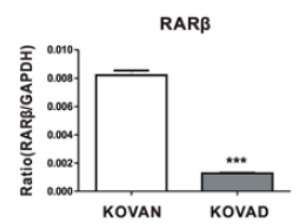

E
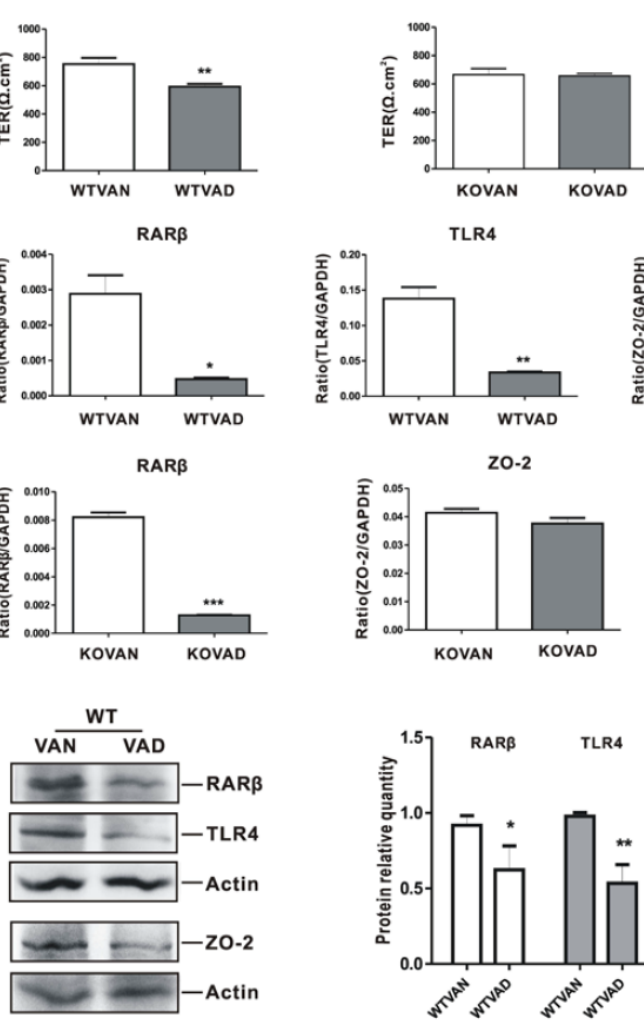

TLR4
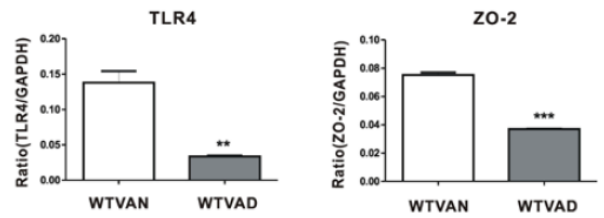

$\mathrm{zo}-2$
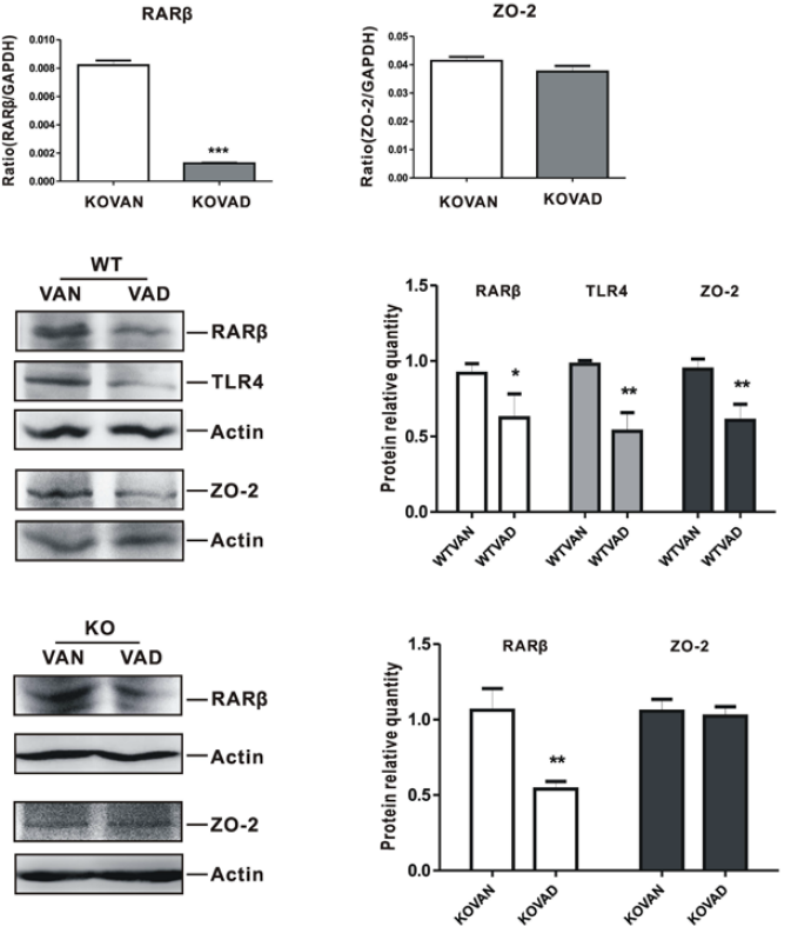

$T L R 4$ was required for the protective effects of RAR $\beta$ on the intestinal epithelial barrier in mice

We used a TLR4 $\%$ mouse model to determine whether TLR4 participates in the mechanism by which VA maintains intestinal epithelial barrier function. We established VAN and VAD models in both WT(WTVAN and WTVAD) and TLR4 $\%$ mice (KOVAN and KOVAD). Fig. 6A shows that serum retinol levels in six-week-old WT and TLR4 $\%$ mice with VA deficiency were lower than those in VAN mice of the same age $\left(\mathrm{n}_{\text {WTVAN }}=9, \mathrm{n}_{\text {WTVAD }}=7, \mathrm{n}_{\text {KOVAN }}\right.$ $=9, n_{\text {KOVAD }}=11$ ), suggesting that the VAD model was successfully established in both WT and TLR4 $\%$ mice. The trends in TER noted in the WTVAN and WTVAD mouse models were similar to those noted in the VAN and VAD rat models. However, colonic TER levels were not different between the TLR4 $\%$ VAN and VAD mouse groups $\left(\mathrm{n}_{\text {KOVAN }}=9, \mathrm{n}_{\text {KovAD }}=11, P=0.8234, \mathrm{t}\right.$ test; Fig. 6B).

RAR $\beta$, TLR4 and ZO-2 mRNA expressions levels were also significantly reduced ( $\mathrm{n}_{\text {WTVAD }}$ $=5, \mathrm{n}_{\text {WTVAN }}=5, P_{\text {RAR } \beta}=0.0103, P_{\text {TLR } 4}=0.0030, P_{\text {zo-2 }}<0.0001, \mathrm{t}$ test; Fig. $6 \mathrm{C}$ ) in the colonic 


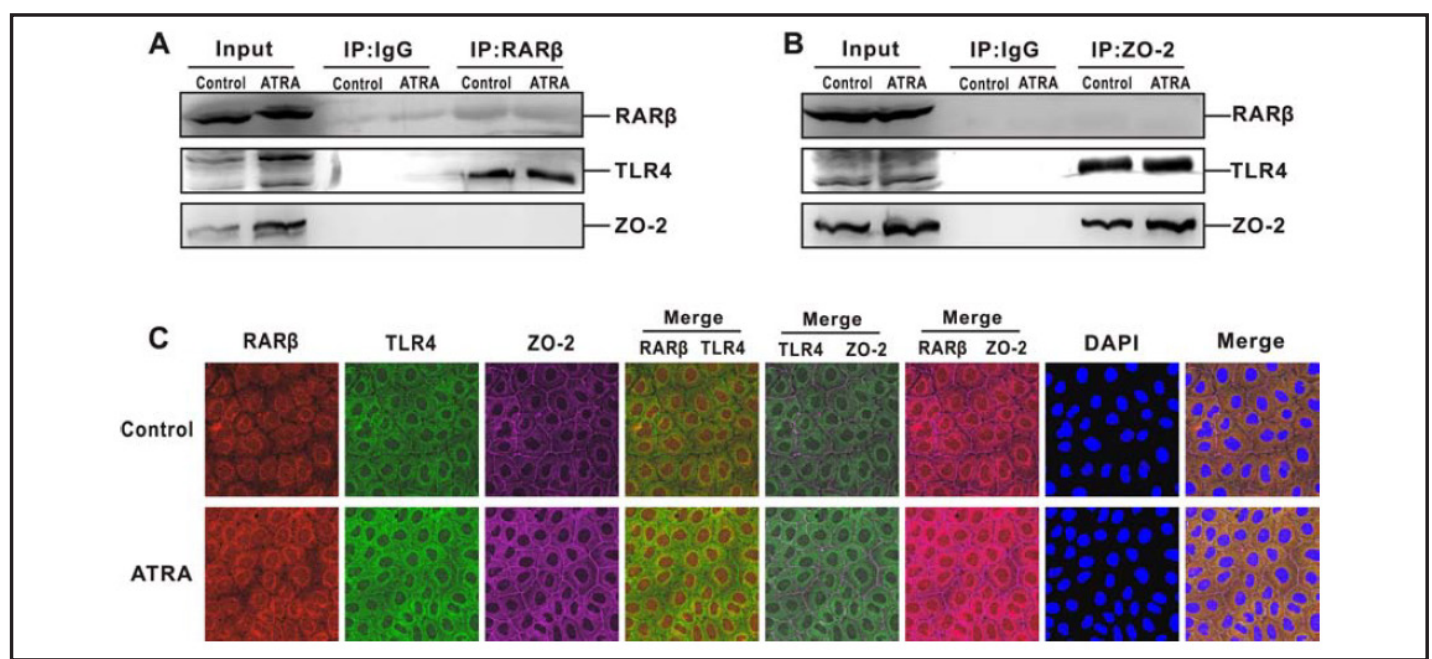

Fig. 7. Interactions among the RAR $\beta$, TLR4 and ZO-2 proteins in Caco-2 cells treated with or without ATRA. (A) RAR $\beta$ could interact with TLR4 but not ZO- 2 in Caco- 2 cells, as determined by co-IP using RAR $\beta$ antibodies. (B) ZO-2 bound to TLR4 in Caco-2 cells; however, ZO-2 did not interact with RAR $\beta$, as determined by co-IP using ZO-2 antibodies. (C) Laser scanning confocal microscopy detected the subcellular distributions of the three proteins in cells treated with or without ATRA using immunofluorescence. The red colour refers to RAR $\beta$, the green colour refers to TLR4, the purple colour refers to ZO-2, and DAPI stained the nuclei of the Caco- 2 cells. RAR $\beta$, TLR4 and ZO-2 were co-localized(original magnification $\times 600$ ). Three independent experiments were performed.

monolayers of WTVAD mice compared with those of WTVAN mice. However, in the KO groups, only RAR $\beta$ mRNA expression levels were lower in KOVAD mice than in KOVAN mice, while TLR4 expression was not detected in either group, and ZO-2 expression levels were not different between the two groups $\left(\mathrm{n}_{\text {KоVAD }}=5, \mathrm{n}_{\text {KOVAN }}=5, P_{\text {RAR } \beta}<0.0001, P_{\text {Z0-2 }}=0.1919\right.$, t test; Fig. 6D). Fig. 6E shows that the expression levels of the three proteins were significantly reduced in WTVAD mice compared with WTVAN mice; however, ZO-2 protein expression levels were not different between the KOVAN and KOVAD groups, while RAR $\beta$ protein expression levels were significantly decreased in KOVAD mice compared with KOVAN mice. These results demonstrate that TLR4 is an important component of the RAR $\beta$ pathway that regulates ZO-2 expression to protect the epithelial barrier.

\section{RAR $\beta$ bound with TLR4 to increase ZO-2 expression levels}

To identify the interactions among RAR $\beta$, TLR4 and ZO-2, we performed coimmunoprecipitation (Co-IP) and ChIP assays involving Caco- 2 cells treated with $5 \mu \mathrm{mol} / \mathrm{L}$ ATRA. Co-IP, which is based on specific antibody and antigen combinations, can determine whether proteins interact under physiological conditions. We used an anti-RAR $\beta$ antibody to precipitate the TLR4 or ZO-2 protein, and as shown in Fig. 7A, RAR $\beta$ bound to the TLR4 protein but did not bind to the ZO-2 protein in Caco-2 cells treated with or without ATRA. Similarly, the ZO-2 protein interacted with TLR4 but not RAR $\beta$ in Caco- 2 cells treated with or without ATRA (Fig. 7B). Moreover, using laser-scanning confocal microscopy, we determined that RAR $\beta$ and TLR4 co-localized near the nucleus and on the membranes of Caco- 2 cells. The TLR4 and ZO- 2 proteins were co-expressed on the cell membrane; however, the RAR $\beta$ and ZO-2 proteins did not appear to be co-expressed in Caco-2 cells treated with or without ATRA (Fig. 7C). Therefore, the interactions among the three proteins that were detected by co-IP were consistent with those observated via confocal microscopy.

ChIP-qPCR is a technique used to study interactions between DNA and proteins. To investigate the mechanism by which RAR $\beta$ regulates TLR4 expression in Caco- 2 cells following ATRA treatment, we performed ChIP assay. As shown in Fig. 8B, RAR $\beta$ was enriched 


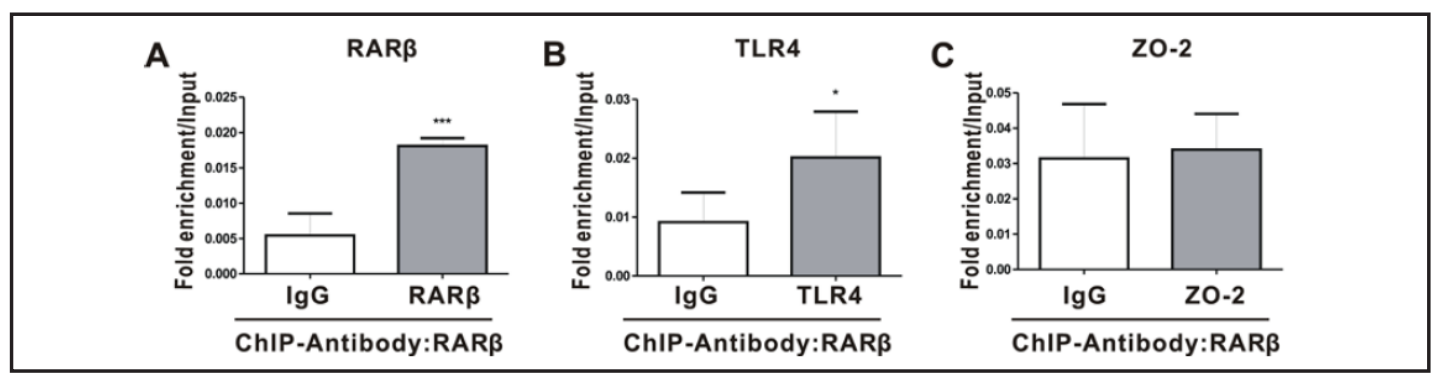

Fig. 8. RAR $\beta$ bound to the promoter region of TLR4 in Caco-2 cells, as determined via ChIP assay using RAR $\beta$ antibodies. (A) RAR $\beta$ levels were confirmed by qPCR using purified DNA enriched with anti-RAR $\beta$ antibodies. ${ }^{*} P<0.05$ versus the IgG group, which served as a negative control. (B) The association between RAR $\beta$ and the promoter region of TLR4 was evaluated using purified DNA enriched with anti-RAR $\beta$ antibodies. ${ }^{*} P<0.05$. (C) Analysis of ZO-2 expression following enrichment with RAR $\beta$ antibodies. No significant difference was noted. The values represent the mean \pm SD of more than three different samples.

in the TLR4 promoter sequence but not the ZO-2 promoter sequence in Caco- 2 cells (Fig. 8C). Taken together, these findings indicate that RAR $\beta$ induced ZO-2 expression by binding to the proximal TLR4 promoter.

\section{Discussion}

The current study addressed whether VAS can rescue gestational VAD-induced colonic epithelial barrier dysfunction and the possible mechanism(s) by which this process occurs. The primary finding of this study was as follows: RA treatment triggered RAR $\beta$ signalling pathway-mediated increases in TLR4 expression levels in the intestinal epithelium to facilitate ZO-2 expression to ameliorate colonic barrier function.

Numerous studies have shown that VA can improve intestinal epithelial integrity when diarrhoea and colitis damage the intestinal epithelium. The protective effects of VA manifest as increases in TER, reductions in intestinal permeability, and improvements in TJ complex expression [32]. Both TER and zonulin are indices of epithelial barrier permeability $[28,29,33]$. TER is directly proportional to intestinal epithelial integrity, and increases in zonulin secretion are followed by corresponding increases in intestinal permeability. Thus, the higher the level of zonulin release, the greater the increase in intestinal permeability. In the present study, we confirmed that RA, a metabolic and functional product of VA in vivo, has protective effects on intestinal epithelial barrier function. When RA increased the TER of the Caco-2 cell monolayer in the current study, intestinal permeability was decreased, and zonulin secretion was reduced. TER was also lower in the colonic epithelial monolayer of VAD rats than in the colonic epithelial monolayer of VAN rats; however, VAS effectively attenuated the intestinal barrier dysfunction caused by gestational VAD. These findings are consistent with the results of a study showing that the incidence of diarrhoea in children was decreased by oral VA administration [9].

TJs play an essential role in maintaining intestinal epithelial integrity. Increasing numbers of studies have determined that VA plays a role in preserving intestinal epithelial structure; however, few in-depth studies on the molecular mechanisms by which VA preserves intestinal epithelial structure have been reported. Occludins, claudins and ZO proteins, which regulate epithelial proliferation, differentiation and permeability, are the major components of TJs [4, 16, 34]. RA enhances occludin, claudin, and ZO-1 expression $[4,32]$. Our current data showed that ATRA treatment increased ZO-2 expression levels in Caco-2 cells. Furthermore, ZO-2 expression levels were reduced or enhanced in the colonic epithelial tissues of VAD or VAS rats, respectively, demonstrating that VA levels impact TJs in the colonic epithelium. 
TLRs recognize intestinal bacteria to maintain mucosal homeostasis. When mucosal homeostasis is disrupted, PKC signalling participates in TLR-induced downstream events $[20,35,36]$. Cario et al suggested that TLR2 activation enhances ZO-1 via PKC, and Gibson et al reported that TLR2 plays a critical role in maintaining intestinal mucosal integrity during infections by bacterial pathogens. TLR2 can prevent epithelial cell apoptosis and maintain ZO-1 localization and functionality in the TJ complex [37]. ZO-1 and ZO-2 have similar structures, as ZO proteins exhibit considerable functional redundancy [38-40]. Our current study showed that TLR4 knockdown in vitro or knockout in vivo induced different changes in ZO-2 expression When TLR4 was knocked down via Ad-siTLR4 infection in Caco-2 cells, ZO-2 expression levels also decreased. However, when TLR4 was knocked out in mice, ZO-2 expression levels did not differ between the VAD and VAN groups. We subsequently confirmed that TLR4 interacted with ZO-2 following ATRA treatment in Caco-2 cells using Co-IP. However, whether TLR4 regulates ZO-2 via PKC signalling will be explored in future studies.

VA can regulate TLRs during the immune response. Blomhoff's group discovered that RA can improve critical immune parameters in CVID-derived B cells stimulated by TLR9 and RP105, findings that support the idea that RA can be combined with TLR stimulation to treat CVID [41, 42]. Eduardo showed that RA-mediated regulation of dendritic cell gastrointestinal activity required MyD88, which is associated with TLR, interleukin (IL)1 , and IL-18 signalling [43]. The present study of the effects of VA on intestinal epithelial integrity revealed that a relationship exists between VA levels and TLRs. We found that VA regulated TLR4 expression levels in the intestinal epithelium both in vivo and in vitro. These findings indicate that VA modulates the immune system.

The primary known function of RA is to regulate gene transcription through nuclear receptors, namely, RARs and retinoic $X$ receptors (RXRs). The RAR family comprises the following three members: $\operatorname{RAR} \alpha, \operatorname{RAR} \beta$ and $\operatorname{RAR} \gamma$ [44]. Osanai et al reported that $\mathrm{RAR} \alpha$ stimulation attenuated epithelial barrier loss in experimental colitis. RA increases E-cadherin and Z0-1 expression levels through RAR $\beta$ in the brain endothelial barrier [45]. We performed experiments demonstrating that ATRA increased RAR $\beta$ expression levels in Caco- 2 cells, results consistent with those of the experiments assessing RAR $\beta$ expression in the colonic epithelial cell monolayer following VA supplementation to the VAD rats. TLR4 and ZO-2 expression levels increased with increasing RAR $\beta$ expression levels in both Caco-2 cells and the colonic epithelial cell monolayer. However, TLR4 knockdown in Caco- 2 cells did not change RAR $\beta$ expression levels but decreased $\mathrm{ZO}-2$ levels. These findings suggest that RAR $\beta$ may be a key facilitator of improvements in intestinal barrier function following ATRA treatment.

Regardless of whether RAR $\beta$ signalling increased or decreased, the changes in TLR4 and ZO-2 expression levels were consistent with those in RAR $\beta$ expression in Caco- 2 cells. Therefore, we speculate that RAR $\beta$ regulated TLR 4 and ZO- 2 to maintain intestinal epithelial integrity. To better understand some of the potential effects of RAR $\beta$ on barrier function, we studied the molecular interactions among these three proteins. The co-IP results, which are shown in Fig. 7A, demonstrated that RAR $\beta$ interacted with TLR4, suggesting that RAR $\beta$ can directly or indirectly combine with TLR4 and that TLR4 interacted with ZO-2; however, RAR $\beta$ did not interact with ZO-2. Moreover, immunofluorescence staining showed that RAR $\beta$ and TLR4 co-localized in the cytoplasm and nucleus and that TLR4 and ZO-2 co-localized on the membranes of Caco- 2 cells. These phenomena were enhanced following ATRA treatment. However, RAR $\beta$ rarely co-localized with ZO-2. Furthermore, we verified that the RAR $\beta$ could bind to the promoter sequence of TLR 4 but not that of ZO-2 in Caco- 2 cells by ChIP assay. These results demonstrate that RAR $\beta$ enhances ZO- 2 expression by binding the TLR4 promoter sequence to regulate TLR4 mRNA transcriptional activity, i.e., the RAR $\beta$ protein combines with the TLR4 promoter DNA sequence. Intriguingly, our finding that ZO-2 expression levels were not affected by decreases in RAR $\beta$ expression levels in KOVAD mice strongly suggests that RAR $\beta$ regulates TLR4 to enhance ZO-2 expression in the colon, most likely through two possible mechanisms. Specifically, our co-IP and immunofluorescence

\section{KARGER}


data suggested that RAR $\beta$ interacts with the TLR4 protein, while our ChIP assay results showed that RAR $\beta$ regulates TLR 4 transcriptional activity. Our next study should focus on the biological functions of the interactions between RAR $\beta$ and TLR4 proteins in the cell nucleus.

\section{Acknowledgements}

This work was supported by grants from the National Natural Science of Foundation of China (81070286, 81470799) and the Science \& Technology Project of Yuzhong District of Chongqing (20120210).

We thank Liu Lan for assisting with the study. Yingying Li, Yuan Gao, and Ting Cui performed the experiments and analysed the data. Ting Yang provided technical guidance regarding the use of HPLC. Yingying Li and Jie Chen wrote the manuscript. Tingyu Li and Jie Chen designed the study. Jie Chen provided financial support for the study. All authors read and approved the final manuscript.

\section{Disclosure Statement}

The authors have no potential conflicts of interest regarding the publication of this manuscript.

\section{References}

1 Clagett-Dame M, DeLuca HF: The role of vitamin A in mammalian reproduction and embryonic development. Annu Rev Nutr 2002;22:347-381.

2 Stephensen CB: Vitamin A, infection, and immune function. Annu Rev Nutr 2001;21:167-192.

-3 Osanai M, Petkovich M: Expression of the retinoic acid-metabolizing enzyme CYP26A1 limits programmed cell death. Mol Pharmacol 2005;67:1808-1817.

-4 Osanai M, Nishikiori N, Murata M, Chiba H, Kojima T, Sawada N: Cellular retinoic acid bioavailability determines epithelial integrity: Role of retinoic acid receptor alpha agonists in colitis. Mol Pharmacol 2007;71:250-258.

5 Maciel AA, Oria RB, Braga-Neto MB, Braga AB, Carvalho EB, Lucena HB, Brito GA, Guerrant RL, Lima AA: Role of retinol in protecting epithelial cell damage induced by Clostridium difficile toxin A. Toxicon 2007;50:1027-1040.

6 Liu X, Li Y, Wang Y, Wang Q, Li X, Bi Y, Liu L, Wei X, Li T, Chen J: Gestational vitamin A deficiency reduces the intestinal immune response by decreasing the number of immune cells in rat offspring. Nutrition 2014;30:350-357.

7 Liu X, Cui T, Li Y, Wang Y, Wang Q, Li X, Bi Y, Wei X, Liu L, Li T, Chen J: Vitamin A supplementation in early life enhances the intestinal immune response of rats with gestational vitamin A deficiency by increasing the number of immune cells. PLoS One 2014;9:e114934.

8 Amit-Romach E, Uni Z, Cheled S, Berkovich Z, Reifen R: Bacterial population and innate immunity-related genes in rat gastrointestinal tract are altered by vitamin A-deficient diet. J Nutr Biochem 2009;20:70-77.

-9 McCullough FS, Northrop-Clewes CA, Thurnham DI: The effect of vitamin A on epithelial integrity. Proc Nutr Soc 1999;58:289-293.

10 Imdad A, Herzer K, Mayo-Wilson E, Yakoob MY, Bhutta ZA: Vitamin A supplementation for preventing morbidity and mortality in children from 6 months to 5 years of age. Cochrane Database Syst Rev 2010;10.1002/14651858.CD008524.pub2Cd008524.

11 Abreu MT: Toll-like receptor signalling in the intestinal epithelium: how bacterial recognition shapes intestinal function. Nat Rev Immunol 2010;10:131-144.

12 Cario E, Podolsky DK: Differential alteration in intestinal epithelial cell expression of toll-like receptor 3 (TLR3) and TLR4 in inflammatory bowel disease. Infect Immun 2000;68:7010-7017. 


\section{Cellular Physiology Cell Physiol Biochem 2017;42:1390-1406 \begin{tabular}{ll|l} 
and Biochemistry Published online: July 17, 2017 & $\begin{array}{l}\text { C } 2017 \text { The Author(s). Published by S. Karger AG, Basel } \\
\text { www.karger.com/cpb }\end{array}$ \\
\hline
\end{tabular}}

13 Cario E, Golenbock DT, Visintin A, Runzi M, Gerken G, Podolsky DK: Trypsin-sensitive modulation of intestinal epithelial MD-2 as mechanism of lipopolysaccharide tolerance. J Immunol 2006;176:4258-4266.

14 Rakoff-Nahoum S, Paglino J, Eslami-Varzaneh F, Edberg S, Medzhitov R: Recognition of commensal microflora by toll-like receptors is required for intestinal homeostasis. Cell 2004;118:229-241.

15 Fukata M, Michelsen KS, Eri R, Thomas LS, Hu B, Lukasek K, Nast CC, Lechago J, Xu R, Naiki Y, Soliman A, Arditi M, Abreu MT: Toll-like receptor-4 is required for intestinal response to epithelial injury and limiting bacterial translocation in a murine model of acute colitis. Am J Physiol Gastrointest Liver Physiol 2005;288:G1055-1065.

-16 Tsukita S, Furuse M, Itoh M: Multifunctional strands in tight junctions. Nat Rev Mol Cell Biol 2001;2:285293.

17 Gonzalez-Mariscal L, Betanzos A, Nava P, Jaramillo BE: Tight junction proteins. Prog Biophys Mol Biol 2003;81:1-44.

18 Tsukita S, Katsuno T, Yamazaki Y, Umeda K, Tamura A, Tsukita S: Roles of ZO-1 and ZO-2 in establishment of the belt-like adherens and tight junctions with paracellular permselective barrier function. Ann N Y Acad Sci 2009;1165:44-52.

19 Umeda K, Ikenouchi J, Katahira-Tayama S, Furuse K, Sasaki H, Nakayama M, Matsui T, Tsukita S, Furuse M, Tsukita S: ZO-1 and ZO-2 independently determine where claudins are polymerized in tight-junction strand formation. Cell 2006;126:741-754.

20 Cario E, Gerken G, Podolsky DK: Toll-like receptor 2 enhances ZO-1-associated intestinal epithelial barrier integrity via protein kinase C. Gastroenterology 2004;127:224-238.

21 Chen J, Rao JN, Zou T, Liu L, Marasa BS, Xiao L, Zeng X, Turner DJ, Wang JY: Polyamines are required for expression of Toll-like receptor 2 modulating intestinal epithelial barrier integrity. Am J Physiol Gastrointest Liver Physiol 2007;293:G568-576.

22 Hidalgo IJ, Raub TJ, Borchardt RT: Characterization of the human colon carcinoma cell line (Caco-2) as a model system for intestinal epithelial permeability. Gastroenterology 1989;96:736-749.

23 Gong M, Bi Y, Jiang W, Zhang Y, Chen L, Hou N, Chen J, Li T: Retinoic acid receptor beta mediates all-trans retinoic acid facilitation of mesenchymal stem cells neuronal differentiation. Int J Biochem Cell Biol 2013;45:866-875.

24 Zhang X, Chen K, Chen J, Liu YX, Qu P, Li TY: Effect of marginal vitamin A deficiency during pregnancy on retinoic acid receptors and N-methyl-D-aspartate receptor expression in the offspring of rats. J Nutr Biochem 2011;22:1112-1120.

25 Jiang W, Yu Q, Gong M, Chen L, Wen EY, Bi Y, Zhang Y, Shi Y, Qu P, Liu YX, Wei XP, Chen J, Li TY: Vitamin A deficiency impairs postnatal cognitive function via inhibition of neuronal calcium excitability in hippocampus. J Neurochem 2012;121:932-943.

-26 Elamin EE, Masclee AA, Dekker J, Pieters HJ, Jonkers DM: Short-chain fatty acids activate AMP-activated protein kinase and ameliorate ethanol-induced intestinal barrier dysfunction in Caco-2 cell monolayers. J Nutr 2013;143:1872-1881.

-27 Cai Y, Wang W, Liang H, Sun L, Teitelbaum DH, Yang H: Keratinocyte growth factor improves epithelial structure and function in a mouse model of intestinal ischemia/reperfusion. PLoS One 2012;7:e44772.

-28 Smith PL: Methods for evaluating intestinal permeability and metabolism in vitro. Pharm Biotechnol 1996;8:13-34.

29 Fasano A: Intestinal permeability and its regulation by zonulin: diagnostic and therapeutic implications. Clin Gastroenterol Hepatol 2012;10:1096-1100.

-30 Abreu MT, Vora P, Faure E, Thomas LS, Arnold ET, Arditi M: Decreased expression of Toll-like receptor-4 and MD-2 correlates with intestinal epithelial cell protection against dysregulated proinflammatory gene expression in response to bacterial lipopolysaccharide. J Immunol 2001;167:1609-1616.

31 Otte JM, Cario E, Podolsky DK: Mechanisms of cross hyporesponsiveness to Toll-like receptor bacterial ligands in intestinal epithelial cells. Gastroenterology 2004;126:1054-1070.

32 Baltes S, Nau H, Lampen A: All-trans retinoic acid enhances differentiation and influences permeability of intestinal Caco-2 cells under serum-free conditions. Dev Growth Differ 2004;46:503-514.

-33 Han C, Ding Z, Shi H, Qian W, Hou X, Lin R: The Role of Probiotics in Lipopolysaccharide-Induced Autophagy in Intestinal Epithelial Cells. Cell Physiol Biochem 2016;38:2464-2478.

-34 Matter K, Aijaz S, Tsapara A, Balda MS: Mammalian tight junctions in the regulation of epithelial differentiation and proliferation. Curr Opin Cell Biol 2005;17:453-458. 


\section{Cellular Physiology Cell Physiol Biochem 2017;42:1390-1406 \begin{tabular}{l|l} 
DOI: 10.1159/000479203 & $\begin{array}{l}\text { O 2017 The Author(s). Published by S. Karger AG, Basel } \\
\text { www.karger.com/cpb }\end{array}$
\end{tabular}}

Li et al.: RAR $\beta$ Regulates TLR4 to Improve Barrier Function

35 Li X, Wang C, Nie J, Lv D, Wang T, Xu Y: Toll-like receptor 4 increases intestinal permeability through upregulation of membrane PKC activity in alcoholic steatohepatitis. Alcohol 2013;47:459-465.

-36 Wardill HR, Gibson RJ, Logan RM, Bowen JM: TLR4/PKC-mediated tight junction modulation: a clinical marker of chemotherapy-induced gut toxicity? Int J Cancer 2014;135:2483-2492.

37 Gibson DL, Ma C, Rosenberger CM, Bergstrom KS, Valdez Y, Huang JT, Khan MA, Vallance BA: Toll-like receptor 2 plays a critical role in maintaining mucosal integrity during Citrobacter rodentium-induced colitis. Cell Microbiol 2008;10:388-403.

-38 Itoh M, Nagafuchi A, Moroi S, Tsukita S: Involvement of ZO-1 in cadherin-based cell adhesion through its direct binding to alpha catenin and actin filaments. J Cell Biol 1997;138:181-192.

39 Ando-Akatsuka Y, Yonemura S, Itoh M, Furuse M, Tsukita S: Differential behavior of E-cadherin and occludin in their colocalization with ZO-1 during the establishment of epithelial cell polarity. J Cell Physiol 1999;179:115-125.

40 Wittchen ES, Haskins J, Stevenson BR: Protein interactions at the tight junction. Actin has multiple binding partners, and ZO-1 forms independent complexes with ZO-2 and ZO-3. J Biol Chem 1999;274:3517935185.

41 Ertesvag A, Aasheim HC, Naderi S, Blomhoff HK: Vitamin A potentiates CpG-mediated memory B-cell proliferation and differentiation: involvement of early activation of p38MAPK. Blood 2007;109:3865-3872.

-42 Eriksen AB, Indrevaer RL, Holm KL, Landskron J, Blomhoff HK: TLR9-signaling is required for turning retinoic acid into a potent stimulator of RP105 (CD180)-mediated proliferation and IgG synthesis in human memory B cells. Cell Immunol 2012;279:87-95.

43 Villablanca EJ, Wang S, de Calisto J, Gomes DC, Kane MA, Napoli JL, Blaner WS, Kagechika H, Blomhoff R, Rosemblatt M, Bono MR, von Andrian UH, Mora JR: MyD88 and retinoic acid signaling pathways interact to modulate gastrointestinal activities of dendritic cells. Gastroenterology 2011;141:176-185.

44 Blomhoff R, Blomhoff HK: Overview of retinoid metabolism and function. J Neurobiol 2006;66:606-630.

-45 Mizee MR, Wooldrik D, Lakeman KA, van het Hof B, Drexhage JA, Geerts D, Bugiani M, Aronica E, Mebius RE, Prat A, de Vries HE, Reijerkerk A: Retinoic acid induces blood-brain barrier development. J Neurosci 2013;33:1660-1671. 